\title{
Analisis Hasil Uji Kompetensi Guru Fisika
}

\author{
Fauzi Bakri ${ }^{1, a)}$, Sabar Budi Raharjo ${ }^{2}$ \\ ${ }^{1}$ Program Studi Pendidikan Fisika, FMIPA, Universitas Negeri Jakarta, \\ ${ }^{2}$ Pusat Penelitian Kebijakan, Badan Penelitian dan Pengembangan, Kemdikbud \\ Email: a)fauzi_bakri@yahoo.co.id
}

\begin{abstract}
This study aims to map the pedagogical competence and professional competence of teachers high school physics teacher competency test participants (UKG) in 2012. The study was conducted qualitatively by exposure method facto supported the survey results in the form of FGD field visits in 2013 to 2015 . The research data is secondary data test results of high school physics teacher competence and FGD data obtained from a visit to several cities in several provinces. Teacher competency test secondary data obtained from the Center for Professional Development of Teachers (PUSBANGPRODIK) Kemdikbud. Teacher competency test was mapped by the standard of essential indicators of teacher competence. For pedagogical competence there are 22 essential indicators, while professional competence are 59 essential indicators. Teacher competency test results in 2012 illustrate that there is one indicator pegagogik at the lowest level, 12 indicators at low levels, while the professional indicator has one indicator at a very low level, 25 indicators at low levels. Based on the results of focus group discussions and field surveys conducted in several high schools in several provinces in 2013 and 2015 found that teachers are less creative in designing scientific learning student-centered. Teachers lack pedagogical training and training to improve the mastery of concepts of physics. Availability of laboratory experiments are also very limited. Textbooks to support the professional competence of teachers of physics that is not owned by the school library.
\end{abstract}

Keywords: competence, pedagogical, professional, UKG, the essential indicator

\begin{abstract}
Abstrak
Penelitian ini bertujuan untuk memetakan kompetensi pedagogik dan kompetensi profesional guru fisika SMA peserta uji kompetensi guru (UKG) tahun 2012. Penelitian dilakukan secara kualitatif dengan metode ekspos fakto yang didukung hasil survei berbentuk FGD dalam kunjungan lapangan tahun 2013 sampai 2015. Data penelitian adalah data sekunder hasil uji kompetensi guru fisika SMA dan data FGD yang didapat dari kunjungan ke beberapa kota di beberapa provinsi. Data sekunder uji kompetensi guru didapat dari Pusat Pengembangan Profesi Pendidik (PUSBANGPRODIK) Kemdikbud. Soal uji kompetensi guru dipetakan berdasarkan indikator esensial standar kompetensi guru. Untuk kompetensi pedagogik terdapat 22 indikator esensial, sedangkan kompetensi profesional terdapat 59 indikator esensial. Hasil uji kompetensi guru pada tahun 2012 memberikan gambaran bahwa ada satu indikator pegagogik pada level paling rendah, 12 indikator pada level rendah, sedangkan indikator profesional memiliki satu indikator pada level sangat rendah, 25 indikator pada level rendah. Berdasarkan hasil FGD dan survey lapangan yang dilakukan di beberapa SMA di beberapa provinsi pada tahun 2013 sampai 2015 didapat bahwa guru kurang kreatif dalam merancang pembelajaran saintifik yang berpusat pada siswa. Guru kurang mendapat pelatihan pedagogik
\end{abstract}


maupun pelatihan peningkatan penguasaan konsep fisika. Ketersediaan alat praktikum di laboratorium juga sangat terbatas. Buku teks untuk menunjang kompetensi profesional guru fisika yang tidak dimiliki oleh perpustakaan sekolah.

Kata-kata kunci: Kompetensi, pedagogik, profesional, UKG, indikator esensial

\section{PENDAHULUAN}

Kualitas lulusan pendidikan tidak terlepas dari kualitas guru.Untuk menghasilkan siswa-siswa yang siap berkompetisi dalam dunia modern, mereka mesti dididik oeh para guru yang memiliki kapasitas dan kompetensi yang memadai dengan kebutuhan masa depan tersebut. Faktanya guru-guru di Indonesia masih jauh dari memadai untuk dapat melakukan perubahan yang mendasar dalam dunia pendidikan (Rizali, 2008, hal 13-14)

Terdapat tiga tugas guru sebagai profesional yang kompeten, yaitu mendidik, mengajar dan melatih. Dalam mendidik, guru harus mengembangkan nilai-nilai hidup. Dalam mengajar guru meneruskan dan mengembangkan ilmu penetahuan, serta dalam melatihberarti guru mengembangkan keterampilan untuk kehidupan siswanya. Untuk dapat melaksanakan tugas dan tanggung jawab dalam menjalankan profesi guru, maka guru harus memiliki beberapa kemampuan dan kompetensi sebagai bagian dari profesionalisme guru (Suyanto, 2013, hal 1). Secara umum, latar pendidikan guru, materi ajar, pengalaman dalam melaksanakan pengajaran sangat erat kaitannya dengan tingkat layanan guru dalam pembelajaran (Sanin, 2015)

Kompetensi guru meliputi kompetensi pedagogik, kompetensi kepribadian, kompetensi sosial, dan kompetensi profesional. Keempat kompetensi ini bersifat holistik dan integratif. Kompetensi pedagogik merupakan kemampuan guru dalam melakukan pengelolaan pembelajaran yang meliputi pemahaman wawasan atau landasan kepemimpinan dan pemahaman terhadap peserta ddiknya yang dilakukan untuk kepentingan peserta didiknya. Kompetensi kepribadian mencakup kepribadian guru yang mantap, stabil, dewasa, arif, bijaksana, berwibawa, berakhlak mulia serta menjadi teladan bagi peserta didik dan masyarakat. Kemapuan sosial merupakan kemampuan guru sebagai bagian dari masyarakat yang sekurang-kurangnya meliputi kompetensi agar mampu berkomunikasi lisan dan tulisan, dan/atau secara isyarat, serat mampu memilih dan memilah dan memanfaatkan alat telekomunikasi yang sesuai secara fungsional. Kompetensi profesional merupakan wujud nyata kemampuan penguasaan atas materi pelajaran secara luas dan mendalam (Sembiring, 2009, hal 3940)

Total guru terhitung Maret 2014 adalah tiga juta lima belas ribu tiga ratus lima belas orang. Sebanyak 1465775 (49 \%) diantaranya adalah guru yang diangkat sampai 2005 dan sudah lulus sertifikasi guru profesional, sisanya guru belum tersertifikasi karena belum lulus (281262 orang atau 9\%), guru yang diangkat setelah 2005 (551021 orang atau 18\%) dan sisanya 24\% lainnya atau 717257 adalah guru tidak tetap (Raharjo, 2014). Data ini menunjukkan bahwa pada Maret 2014 hampir separuh guru yang mengajar dari jenjang PAUD sampai SMTA sudah dinyatakan sebagai guru profesional dengan sertifikat pendidiknya.

Pusat Pengembangan Profesi Pendidik (PUSBANGPRODIK) Kemdikbud merilis data bahwa pada tahun 2012 guru yang mengikuti uji kompetensi guru (UKG) 878.133 orang. Capaian kompetensi pedagogi rata-rata 44,46 dengan nilai minimal 0,00 dan tertinggi 100,00 dengan standar deviasi 13,48. Capaian kompetensi profesional juga tidak jauh berbeda nilai minimal 0,00 dan tertinggi 100,00 dan rata-rata didapat 46,42 serta standar deviasi 12,71.Guru SMA yang mengikuti UKG sebanyak 131.052 orang. Rata-rata capaian kompetensi pedagogik guru tersebut adalah 45,08 sedangkan kompetensi profesional sebesar 48,91 dan rata-rata keduanya adalah 47,72. Tahun 2013 guru yang mengikuti UKG 561.856 orang dan 37.574 diantaranya adalah guru SMA . Hasil UKG 2013 untuk guru SMA adalah dengan rata-rata capaian kompetensi pedagogik 49,86, kompetensi profesional 54,03 dan rata-rata keduanya 52,77 (Raharjo, 2014).

Data yang hasil UKG ini perlu ditindaklanjuti dengan menganalisis capaian UKG pada setiap bidang studi. Hasil analisis ini sangat bermanfaat bagi lembaga pendidikan yang menghasilkan guru agar kualitas guru yang dihasilkan lebih kompeten. 


\section{METODE PENELITIAN}

Makalah ini adalah bagian kecil dari penelitian tentang capaian standar nasional pendidikan (SNP) pada jenjang pendidikan menengah (SMA) yang dilakukan bersama tim peneliti dari Pusat Penelitian Kebijakan, Badan Penelitian dan Pengembangan, Kementerian Pendidikan dan Kebudayaan Republik Indonesia.

\section{A. Bentuk penelitian}

Penelitian ini adalah penelitian deskriptif dengan bentuk ekspost fakto. Penelitian ekspost fakto adalah penemuan empiris yang dilakukan secara sistematis, peneliti tidak melakukan kontrol terhadap variabel bebas, karena manifestasinya sudah terjadi atau variabel tersebut secara inheren tidak dapat dimanipulasi. UKG sudah dilakukan tahun 2012 oleh Pusat Pengembangan Profesi Pendidik (PUSBANGPRODIK) Kemdikbud, sehingga tidak ada perlakukan yang diberikan terhadap populasi maupun sampel.

\section{B. Data Penelitian}

Data utama yang digunakan dalam penelitian ini adalah data hasil UKG yang dilakukan PUSBANGPRODIK Kemdikbud. Data pendukung adalah pendapat yang diberikan guru terhadap pelaksanaan UKG yang sudah dilakukannya.

\section{Sumber Data}

Data yang digunakan dalam penelitian ini bersumber dari hasil uji kompetensi guru oleh (PUSBANGPRODIK) Kemdikbud. Pendapat guru tentang kesulitan mereka dalam menjawab soalsoal UKG didapat dari FGD yang dilakukan bersama guru-guru fisika di beberapa daerah kabupaten/kota di beberapa provinsi. Untuk data pendapat guru terhadap hasil UKG, dilakukan dalam bentuk forum grup diskusi (FGD) dengan guru-guru fisika di sela kegiatan penelitian capaian standar nasional pendidikan tahun 2013 sampai tahun 2015. Tahun 2013 dilakukan di Katingan Provinsi Kalimantan Tengah, tahun 2014 di Prabumulih Sumatera Selatan dan Binjai Sumatera Utara, dan tahun 2015 ini di Lombok Barat Nusa Tenggara Barat serta Muara Enim Sumatera Selatan

\section{HASIL DAN PEMBAHASAN}

Penguasaan kompetensi pedagogik dan kompetensi profesional dihitung dari seberapa banyak indikator kompetensi tersebut yang dijawab benar oleh peserta/guru (dalam satuan persen). Kategori sangat rendah $(\leq 20 \%)$; rendah $(21-40 \%)$; sedang $(41-60 \%)$; tinggi $(61-80 \%)$; sangat tinggi (> 80\%). UKG tahun 2012 untuk guru fisika memberikan soal dalam 22 indikator untuk uji kemampuan pedagogik dan 59 indikator untuk uji kemampuan profesional. Rentangan capaian UKG untuk setiap indikator kompetensi pedagogik dan kompetensi profesional tahun 2012 adalah seperti pada GAMBAR 1 .
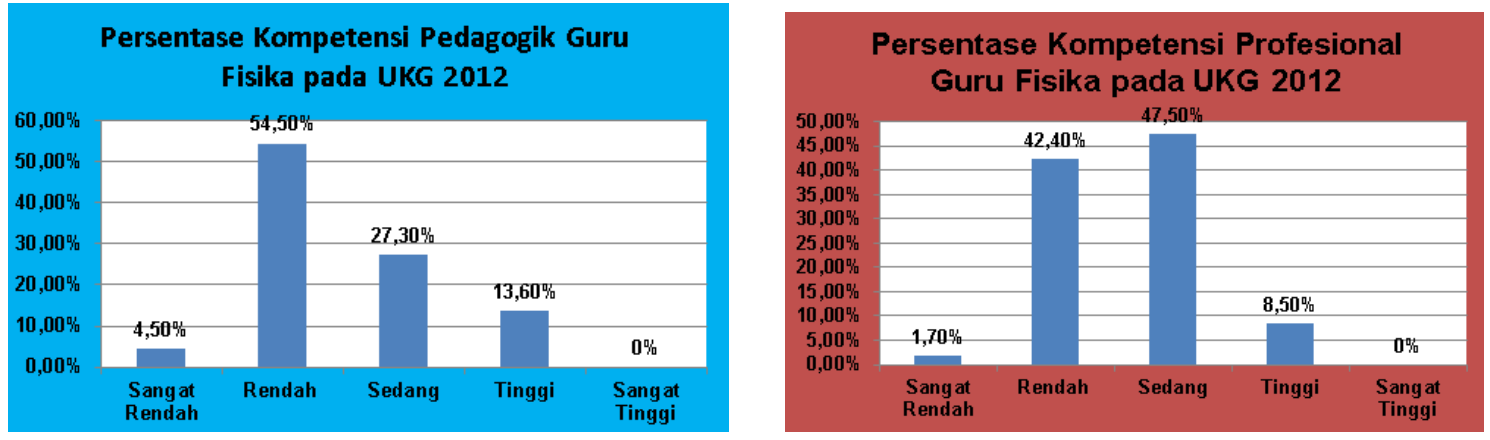

GAMBAR 1. Persentase indikator kompetensi pedagogik dan profesional UKG 2012 untuk guru fisika 
Dari gambar 1 terlihat bahwa tidak satupun soal dari indikator kompetensi pedagogik maupun profesional yang lebih dari $80 \%$ guru menjawab benar. Untuk kemampuan guru yang sangat rendah (kurang dari $21 \%$ jumlah guru yang menjawab benar) dalam kompetensi pedagogik adalah untuk indikator "menentukan tingkat kesukaran dan daya pembeda dari sebuah soal obyektif", yang hanya dapat dijawab benar oleh 19,23\% peserta UKG, sedangkan kompetensi profesional adalah indikator" Membaca hasil pengukuran yang ditunjukkan oleh sekala jangka sorong" yang hanya dapat dijawab benar oleh $17,14 \%$ peserta UKG.

Untuk indikator yang capaian guru fisika tergolong rendah baik kompetensi pedagogik maupun kompetensi profesional seperti gambar 2. Untuk kompetensi pedagogik terdapat 12 indikator yang jumlah guru menjawab benar pada rentang antara $20 \%$ sampai $40 \%$, sedangkan kompetensi profesional terdapat 25 indikator. Kompetensi pedagogik yang capaiannya rendah adalah sesuai grafik: (1) membedakan karakteristik PTK dengan penelitian formal; (2) menentukan bentuk soal tes yang cocok untukMengetahui perkembangan unjuk kerja peserta didik; (3) menentukan materi pembelajaran berdasarkan salah satu rumusan kompetensi dasar; (4) mengidentifikasi tahapan PTK berdasarkan kegiatan yang sedang dilakukan guru dalamMelaksanakan PTK tersebut; (5) menjelaskan konseptualisasi pembelajaran fisika yang mendidik; (6) menjelaskan pelaksanaan beban belajar dalam bentuk penugasan terstruktur (PT) dan kegiatan mandiri tidak terstruktur (KMTT); (7) menjelaskan prinsip menyeluruh dan berkesinambungan dalam penilaian hasil belajar; (8) menjelaskan salah satu bentuk aktifitas guru untuk mengidentifikasi bekal ajar awal peserta didik; (9) Menjelaskan terjadinya belajar bermakna menurut Jerome Bruner (10) Menjelaskan tujuan kegiatan apersepsi dalam suatu pembelajaran; (11) menyebutkan urutan empat langkah pokok dalamMelakukan PTK; (12) Merumuskan contoh tujuan pembelajaran untuk suatu tema atau materi pembelajaran.
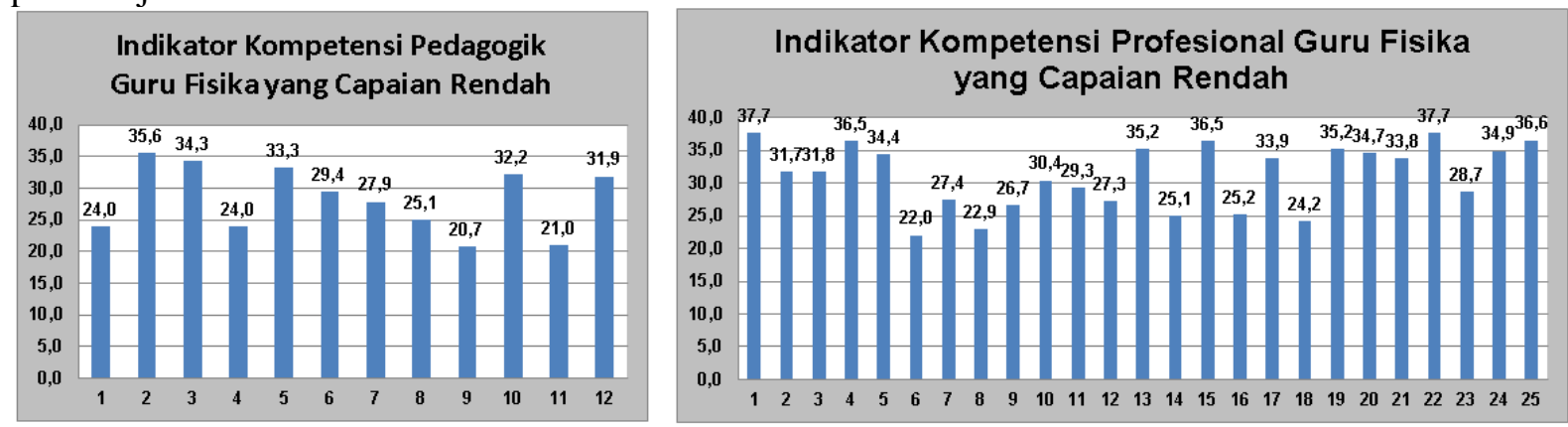

GAMBAR 2. Indikator kompetensi pedagogik dan profesional yang capaian UKG yang rendah

Untuk kompetensi profesional, capaian guru fisika yang tergolong rendah ada pada kompetensi: (1) memprediksi pola grafik perubahan tegangan (V) dan kuat arus (i) dari sebuah lampu pijar; (2) menentukan energi kinetik maksimum foto elektron pada frekuensi tertentu berdasarkan grafik energi kinetik maksimum fungsi frekuensi; (3) menentukan hambatan berdasarkan tegangan catu daya dan kuat arus yang ditunjukkan oleh amperemeter; (4) menentukan keadaan akhir campuran es dan air yang memiliki massa dan suhu awal berbeda; (5) menentukan kecepatan benda setelah mengalami tumbukan tidak elastis (6) menentukan kecepatan dan percepatan rata-rata gerak benda yang lajunya konstan dengan lintasan tidak lurus; (7) menentukan kuat arus yang mengalir di suatu hambatan dalam suatu rangkaian tertutup yang majemuk.; (8) menentukan kuat arus yang mengalir pada lampu dengan spesifikasi tertentu yang dipasang dalam suatu rangkaian tertutup; (9) menentukan panjang lintasan bola yang dilemparkan bolak-balik oleh dua orang yang bergerak semakin dekat dengan kecepatan konstan; (10) Menentukan perbandingan jarak duaMuatan berdasarkan perbandinganMuatan dan resultan kuatMedan yang dihasilkan oleh ke duaMuatan tersebut; (11) menentukan perbandingan percepatan gravitasi benda langit, berdasarkan perbedaan massa dan jarijarinya; (12) menentukan perbandingan tegangan antara dua hambatan yang disusun dalam suatu rangkaian tertutup; (13) menentukan percepatan dan tegangan tali pada sistem beberapa benda yang saling dihubungkan melalui katrol; (14) menentukan perubahan pembesaran mikroskop berdasarkan pergeseran lensa okuler; (15) menentukan salah satu muatan listrik berdasarkan perbandingan jarak dan potensial yang dihasilkan oleh ke dua muatan tersebut; (16) menentukan tegangan pada salah satu komponen dari rangkaian RLC secara seri; (17) menentukan tinggi maksimum gerak suatu 
benda yang ditarik oleh benda jatuh melalui sebuah katrol tetap; (18) menentukan waktu tertangkapnya pencuri yang dikejar polisi berdasarkan jarak, perbedaan kecepatan dan waktu awal mereka mulai begerak; (19) menentukan massa beban yang diperlukan untuk menyeimbangkan batang tuas melalui sistem satu katrol tetap; (20) menggambar pola grafik pengaruh massa terhadap kalor jenis dan kapasitas kalor suatu benda; (21) menjelaskan gerak benda berdasarkan grafik kecepatan fungsi waktu; (22) menjelaskan karakteristik energi getaran harmonik berdasarkan pola grafik energi dan simpangannya; (23) menjelaskan karakteristik gaya-gaya yang bekerja pada benda terapung di permukaan zat cair: (24) menyebutkan contoh unsur radioaktif yang dugunakan untuk mendiagnosa kelenjar tiroid: (25) menyebutkan salah satu karakteristik gerak melingkar beraturan

Terdapat 6 indikator kompetensi pedagogik yang jumlah guru menjawab benar pada level sedang yaitu antara $40 \%$ sampai $60 \%$, sedangkan kompetensi profesional terdapat 28 indikator. Hanya 3 indikator kompetensi pedagogik yang jumlah guru menjawab benar pada level tinggi yaitu antara $60 \%$ sampai $80 \%$, sedangkan kompetensi profesional terdapat 5 indikator. Indikator kompetensi pedagogik yang lebih dari $60 \%$ peserta menjawab benar, yaitu (1) menjelaskan hakekat penerapan pendekatan keterampilan proses dalam pembelajaran IPA $(68,86 \%)$; (2) menjelaskan pengertian bahan ajar (75,89\%); dan (3) menyebutkan prinsip penilaian hasil belajar yang digunakan dalamMenentukan KKM mata pelajaran (60,54\%). Kompetensi profesional yang lebih dari $60 \%$ peserta UKG menjawab benar adalah (1) menentukan ketelitian berdasarkan skala utama dan nonius jangka sorong (65,76\%); (2) menjelaskan cara perpindahan kalor pada fluida $(77,24 \%)$; (3) menjelaskan syarat merangkai shunt agar daya ukur amperemeter dapat diperbesar $(62,72 \%)$; (4) menyebutkan salah satu contoh penggunaan gelombang elektromagnetik dalam kehidupan sehari-hari $(64,82 \%)$; dan (5) menyebutkan sifat-sifat sinar radioaktif pada saat berinteraksi dengan materi $(64,05 \%)$

Akar permasalahan hasil UKG guru fisika SMA ini berdasarkan hasil diskusi dengan beberapa guru di kabupaten Katingan Kalimantan Timur, Prabumulih dan Muara Enim Sumatera Selatan, Binjai Sumatera Utara dan Lombok Barat NTB memberikan hasil bahwa faktor yang menyebabkan rendahnya kompetensi pedagogik guru fisika SMA adalah (1) guru fisika (83\%) menyatakan tidak mendapat pelatihan pengembangan program pembelajaran sebelum adanya program PLPG dan K-13; (2) kompetensi yang paling rendah tentang analisis soal-soal ujian dinyatakan guru (76\%) bahwa mereka tidak mempunyai waktu dan keahlian untuk melakukan analisis tingkat kesukaran, daya beda, validitas dan reabilitas soal-soal yang diujikan baik formatif maupun sumatif; (3) kompetensi lainnya yang capaiannya rendah karena guru-guru tidak mempunyai keahlian dalam menulis laporan penelitian tindakan kelas walaupun mereka semua menyatakan bahwa selalu melakukan perbaikan pembelajaran jika peserta didik mengalami kesulitan dalam pembelajaran; (4) soal-soal teori adalah salah satu sumber rendahnya hasil UKG para guru-guru tersebut. Hal sama juga didapat untuk kompetensi profesional. Faktor yang menyebabkan rendahnya kompetensi profesional guru adalah (1)kemampuan guru dalam menggunakan dan mengkalibrasi alat-alat ukur masih rendah. Didapat bahwa 95\% guru-guru sangat membutuhkan pelatihan penggunaan dan kalibrasi alat-alat ukur; (2) ada 25 indikator yang capaian kompetensi guru fisika rendah. guru-guru mengeluhkan soal UKG profesional guru fisika karena mencakup semua materi fisika dari SMP sampai SMA, sedangkan guru-guru (80\%) hanya menguasai materi fisika sesuai kelas yang diampunya; (3) guru-guru (97\%) menyatakan bahwa tidak pernah mendapat pelatihan kajian materi fisika sejak lulus pendidikan; (4) sebagian guru-guru (17\%) mempunyai latar belakang bukan pendidikan fisika; (5) sebagian besar guru (95\%) tidak mempunyai buku selain buku pegangan sesuai dengan kelas yang diampunya; (6) aktivitas MGMP di daerah sangat rendah, hanya 1 kali sebulan dan tidak adanya dana dari pemerintah.

\section{KESIMPULAN}

Berdasarkan analisis dan pembahasan yang dilakukan terhadap kompetensi pedagogik dan kompetensi profesional guru fisika SMA dapat disimpulkan bahwa:

1. Rendahnya hasil UKG pedagogik guru fisika karena kurangnya frekuensi pelatihan 
2. Rendahnya hasil UKG profesional guru fisika karena kurangnya pelatihan guru serta tidak aktifnya kegiatan MGMP

3. Rendahnya jumlah buku-buku pendukung dan pengayaan guru baik yang dimiliki sekolah maupun perorangan guru

4. Kurang terampilnya guru-guru dalam mengelola dan menggunakan alat-alat lab fisika

\section{SARAN}

Untuk peningkatan kompetensi guru di masa yang akan datang, maka disarankan bahwa:

1. LPTK harus aktif dalam membina guru-guru untuk meningkatkan kemampuan pedagogik maupun profesional

2. LPTK harus menyusun program pelatihan guru-guru untuk untuk meningkatkan kemampuan pedagogik maupun profesional

3. Pemerintah daerah harus lebih memperhatian peningkatan kualitas guru-guru

4. Pemerintah daerah harus menyediakan dana pembinaan guru-guru baik untuk pelatihan singkat maupun studi lanjut di dalam maupun luar negeri

5. Pemerintah daerah harus menyediakan dana untuk menunjang kegiatan guru-guru

\section{UCAPAN TERIMAKASIH}

Makalah ini adalah bagian dari penelitian Kajian Ketercapaian Standar Nasional Pendidikan jenjang pendidikan menengah yang dilakukan Pusat Penelitian dan Kebijakan (Puslitjak Balitbang Kemdikbud) tahun 2013 sampai 2015. Untuk itu ucapan terima kasih disampaikan kepada kepala Balitbang dan Kepala Puslitjak yang telah memberikan kepercayaan untuk ikut bagian dalam penelitian ini.

\section{REFERENSI}

Raharjo, Sabar Budi, Analisis Profesionalisme Guru, Pusat Penelitian Kebijakan, Balitbang, Kemdikbud, Nopember 2014

Rizali, Ahmad, Indra Djati Sidi, Satria Dharma, Dari Guru Konvensional Menuju Guru Profesional, Prosiding, Grasindo Jakarta, 2008, hal 13-14

Sanin, Mehmet, Arthur L. White, Teachers 'Perceptions Related to Characteristics of Professional Environment for Teaching, Eurasia Journal of Mathematics Sciences\& Technology Education, June 2015, Vol 11 (3) p 559-575

Sembiring, M. Gorky, Mengungkap Rahasia dan Tips Manjur Menjadi Guru Sejati, Best Publisher, Yogyakarta, 2009, hal 39-40

Suyanto dan Asep Jihad, Guru Profesional; Strategi Meningkatkan Kualitas Guru di Era Global, Esensi, Jakarta, 2013, hal 1 